\title{
Article
}

\section{Oral Inflammation, Tooth Loss, Risk Factors, and Association with Progression of Alzheimer's Disease}

Singhrao, Simarjit Kaur, Harding, Alice, Simmons, Tal, Robinson, Sarita Jane, Kesavalu, Lakshmyya and Crean, Stjohn

Available at http://clok.uclan.ac.uk/11880/

Singhrao, Simarjit Kaur ORCID: 0000-0001-9573-5963, Harding, Alice, Simmons, Tal, Robinson, Sarita Jane ORCID: 0000-0002-4237-5412, Kesavalu, Lakshmyya and Crean, Stjohn ORCID: 0000-0001-9336-8549 (2014) Oral Inflammation, Tooth Loss, Risk Factors, and Association with Progression of Alzheimer's Disease. Journal of Alzheimer's Disease, 42 (3). pp. 723-737. ISSN $1387-2877$

It is advisable to refer to the publisher's version if you intend to cite from the work. http://dx.doi.org/10.3233/JAD-140387

For more information about UCLan's research in this area go to

http://www.uclan.ac.uk/researchgroups/ and search for < name of research Group>.

For information about Research generally at UCLan please go to http://www.uclan.ac.uk/research/

All outputs in CLoK are protected by Intellectual Property Rights law, including Copyright law. Copyright, IPR and Moral Rights for the works on this site are retained by the individual authors and/or other copyright owners. Terms and conditions for use of this material are defined in the policies page. 


\section{Review}

\section{Oral Inflammation, Tooth Loss, Risk Factors, and Association with Progression of}

Alzheimer's Disease

Sim K. Singhrao ${ }^{\mathrm{a}}$, Alice Harding ${ }^{\mathrm{b}}$, Tal Simmons ${ }^{\mathrm{c}}$, Sarita Robinson ${ }^{\mathrm{d}}$, Lakshmyya Kesavalu ${ }^{\mathrm{e},}$, StJohn Crean ${ }^{\text {b,* }}$

${ }^{\mathrm{a}}$ Oral \& Dental Sciences Research Group, School of Medicine and Dentistry, University of Central Lancashire, Preston, UK

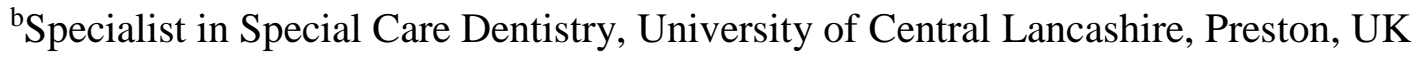
'School of Forensic and Investigative Sciences, University of Central Lancashire, Preston, UK

${ }^{\mathrm{d} S c h o o l ~ o f ~ P s y c h o l o g y, ~ U n i v e r s i t y ~ o f ~ C e n t r a l ~ L a n c a s h i r e, ~ P r e s t o n, ~ U K ~}$

eDepartment of Periodontology, College of Dentistry, University of Florida, Gainesville, Florida, USA

*These authors contributed equally to this work.

Running title: Pathways and factors affecting AD

Accepted 14 April 2014

Correspondence to: Dr. Sim K. Singhrao, Oral \& Dental Sciences Research Group, School of Medicine and Dentistry, University of Central Lancashire, Preston, UK; Tel: +44 (0) 1772 895137, Fax: +44 (0) 1772 892965, SKSinghrao@uclan.ac.uk 


\begin{abstract}
Periodontitis is a polymicrobial chronic inflammatory disease of tooth-supporting tissues with bacterial etiology affecting all age groups, becoming chronic in a subgroup of older individuals. Periodontal pathogens Porphyromonas gingivalis, Tannerella forsythia, and Treponema denticola are implicated in the development of a number of inflammatory pathologies at remote organ sites, including Alzheimer's disease (AD). The initial inflammatory hypothesis proposed that $\mathrm{AD}$ hallmark proteins were the main contributors of central nervous system (CNS) inflammation. This hypothesis is expanding to include the role of infections, lifestyle, and genetic and environmental factors in the pathogenesis of AD. Periodontal disease (PD) typifies a condition that encompasses all of the above factors including pathogenic bacteria. These bacteria not only are the source of low-grade, chronic infection and inflammation that follow daily episodes of bacteremia arising from everyday tasks such as brushing, flossing teeth, chewing food, and during dental procedures, but they also disseminate into the brain from closely related anatomical pathways. The long-term effect of inflammatory mediators, pathogens, and/or their virulence factors, reaching the brain systemically or otherwise would, over time, prime the brain's own microglia in individuals who have inherent susceptibility traits. Such susceptibilities contribute to inadequate neutralization of invading agents, upon reaching the brain. This has the capacity to create a vicious cycle of sustained local inflammatory milieu resulting in the loss of cytoarchitectural integrity and vital neurons with subsequent loss of function (deterioration in memory). The possible pathways between PD and AD development are considered here, as well as environmental factors that may modulate/exacerbate AD symptoms.
\end{abstract}

Keywords: Alzheimer's disease, inflammation, oral health, periodontal disease 


\section{Introduction}

Alzheimer's disease (AD), a form of dementia, is the most common neurodegenerative disease worldwide [1]. The prevalence of AD increases exponentially with age, rising from 3\% among the 65 to 74 year age group and to almost 50\% among those around 85 years and older [2, 3]. Mental deterioration is slow but progressive, contributing to poor memory, disorientation, confusion, and eventually profound dementia. Susceptible individuals can take decades before clinically presenting with the disease. This implies that the etiology of AD is heterogeneous and that the importance of finding new risk factors for development in the case of late-onset AD remains a priority.

Although partial efficacy of non-steroidal anti-inflammatory drugs in some AD patients [4, 5] gave rise to the inflammatory hypothesis that accounts for the intrinsic elements of CNS inflammation [6], support also exists for the extrinsic inflammatory mediators. The elderly, for example, having suffered multiple episodes of recurrent infections, can present with dementia like clinical symptoms in likely late-onset AD cases [7] as well as those subjects with confirmed clinical diagnoses of $\mathrm{AD}[8,9]$.

The innate immune responses suggest extrinsic inflammatory cytokines are involved in exacerbating neurocognition [9] and cytokine-related genes are being implicated in the susceptibility to inflammation in late-onset $\operatorname{AD}[10,11,12]$. Furthermore, human brain tissue specimens from postmortem AD patients demonstrate evidence for neuroinflammation via the activated complement system as C1q, C3b, and reactive oxygen species are all involved in the amyloid fibril formation $[11,13,14]$. These observations are strengthened by genome-wide studies supporting the role of innate immune components such as complement receptor 1 (CR1) and a fluid-phase regulatory protein clusterin $[15,16]$. 


\section{Pathological Hallmarks of Alzheimer's Disease}

In $\mathrm{AD}$, marked neuronal loss is observed in the hippocampus where high densities of the classical hallmark lesions are initially observed [17]. An accumulation of intraneuronal neurofibrillary tangles (NFTs) and extracellular amyloid- $\beta(\mathrm{A} \beta$ ) plaques are the two easily demonstrated histological features of AD brains [18]. Synaptic dysfunction is considered as one of the earliest structural defects [19]. Specifically, NFTs indicate the severity of disease with A $\beta$ plaques depicting disease progression [17]. NFTs in neurons constitute hyperphosphorylated tau protein that alters the polymerization and stability of microtubules [20]. The loss of synapses between neurons correlates well with cognitive decline [19]. The cumulative knock-on effect of these cytoarchitectural changes is compromised protein-protein interactions with other cytoskeletal elements eventually leading to further synaptic loss and the demise of the NFTbearing neurons $[17,18,20,21]$.

Amyloid plaques are largely made up of fibrillary $A \beta$ peptides $A \beta_{40 / 42}$ amino-acid residues and are the result of $\alpha$-, $\beta$-, and $\gamma$-secretase enzymes cleaving the transmembrane amyloid- $\beta$ protein precursor expressed by all CNS cells. The proteolytic fragment consisting of the last 28 residues of the amyloid- $\beta$ protein precursor ectodomain prior to the membrane and including the first 12 to -14 residues of the transmembrane region generate $A \beta_{40 / 42}$ amino-acid residues that lead to deposition of extracellular, insoluble fibrillar $A \beta$. Clearing insoluble $A \beta$ peptides from the brain involves phagocytosis by microglial cells [22, 23], an activity that invariably fails with the consequences of further accumulation of fibrillary $\mathrm{A} \beta$.

$\mathrm{A} \beta$ peptides and insulin are known substrates of an insulin-degrading enzyme [24, 25]. Both of these proteins are important in the pathogenesis of $\mathrm{AD}$ and type II diabetes mellitus, respectively. Literature supports the risk-factor relationship between type II diabetes with 
increased risk of cognitive impairment and dementia via its potential pro-inflammatory toxicity from perturbed glucose metabolism [26]. However, it is not clear if $A \beta$ itself promotes insulin resistance in $\mathrm{AD}$ with the generation of subsequent oxidative stress, reactive oxygen species, and related pro-inflammatory cascades [27]. Streptozotocin used for generating experimental diabetic rats as a model for investigating late-onset $\mathrm{AD}$ in relation to insulin resistance is a toxin derived from Streptomyces species of bacteria [28]. It is, therefore, plausible to suggest that an initial microbial trigger may be responsible for insulin resistance and the subsequent deposition of $A \beta$ in late-onset $\mathrm{AD}$.

$\mathrm{A} \beta$ plaques can be observed in the brains of cognitively intact individuals, but they are fewer and are generally of the diffuse (A $\left.\beta_{40}\right)$ type, which so far appear to have little pathological significance. Of the two forms of amyloid, fibrillary $A \beta$ is regarded as being neurotoxic [29] and in vitro studies have shown it to lyse all types of cells by apoptosis [30]. Evidence from neuroradiological and neuropathological investigations link this hallmark $\left(\mathrm{A} \beta_{40 / 42}\right)$ to the initiation of intracerebral inflammatory response in the inherited forms of AD as well as lateonset $\mathrm{AD}[14,31,32]$.

The inflammatory element of the disease may be a significant risk factor for late-onset AD, specifically as innate immune components such as C1q and C3b are involved with plaque maturation $[11,13]$. The relevance of detecting $\mathrm{C} 1 \mathrm{q}$ and $\mathrm{C} 3 \mathrm{~b}$ within $\mathrm{A} \beta_{40 / 42}$ also draws attention to the cellular mechanisms involved with regulating inflammation in neurodegeneration and in clearing $A \beta_{40 / 42}$. The inflammatory components corroborate data from genetic studies proposing a relationship between $\mathrm{AD}$ and cytokine polymorphisms [12, 33], as well as the complement proteins such as clusterin and CR1 in its pathogenesis $[15,16]$. With respect to the complement activation cascade, CR1 is a membrane-associated complement inhibitory protein that binds C4b 
and C3b acting at the $\mathrm{C} 3 / \mathrm{C} 5$ convertase stage of the alternative and classical complement pathway, and clusterin is a fluid-phase protein that interferes with the assembly of the lytic membrane attack complex. Decrease in clearance of the lesion by the innate immune system contributes to bystander damage that promotes a vicious cycle of chronic intra-cerebral inflammatory (high endogenous levels of inflammatory mediators) response [14, 34].

\section{What is Intra-Cerebral Inflammation?}

In the past the brain was considered as an "immunoprivileged organ," as elements of the immune system [such as neutrophils, naive T cells (adaptive immune system), plasma proteins, and extra-cerebral-toxins to prevent inappropriate glial cell activation] cannot cross the bloodbrain barrier (BBB). However, it is now understood that the circumventricular organs are not subject to the BBB [35], a region of the brain where infections (both systemic and direct via the trigeminal and olfactory nerve pathways (see Figure 1) and inflammatory mediators can access the brain [36-38].

The brain deals with inappropriate toxins derived locally (A $\beta$ deposits) or from extracerebral sources (infectious agents) using its own innate immune system consisting of ependymal cells, microglia, astrocytes, and oligodendrocytes [39]. Normally these cells regulate the production and uptake of endotoxins and secrete trophic factors that nurture the CNS cells and protect their functions [40]. However, following physical damage and/or invasion by foreign agents (lipopolysaccharide, LPS), glial cells (specifically microglia) bearing the LPS receptor (CD14) and the highly conserved toll-like receptors 2 and 4 (TLR 2 and 4) undergo a number of phenotypic (resting to activated state) and functional changes. Key morphological changes include thickening and shortening of branching processes attached to a hypertrophic glial cell 
body [41]. Once activated, microglia upregulate the expression of MHC class II molecules along with the secretion of pro-inflammatory cytokines (TNF- $\alpha$ and IL- $\beta$ ), complement proteins, quinolinic acid, arachidonic acid and its metabolites, nitric oxide, platelet activating factor, $\alpha$ and $\beta$ chemokines excitatory amino acids, and free radicals [14]. When these innate factors are secreted by microglia, a local CNS inflammatory response is mounted.

In $\mathrm{AD}$ brains, $\mathrm{A} \beta$ is recognized as a nidus for intracerebral inflammation placing chronic neuroinflammation downstream of this primary hallmark $[13,14]$. However, this view is changing, especially with late-onset $\mathrm{AD}$ cases as the importance of the innate immune molecules is being uncovered by genome-wide studies [11]. If nerve cell death and chronic CNS inflammation are common precursors of the development of dementia, explaining equivalent numbers of $\mathrm{A} \beta$ deposits and NFTs in clinical and subclinical AD in the very elderly who bypass dementia is important [42-45] and adds further complications to the etiological nature of AD. Even $A \beta$ in subclinical $A D$ subjects, which initiates intracerebral inflammation [11, 46, 47], appears not to lead to clinical decline in cognition. One possible explanation for the lack of cognitive decline could lay in the inflammatory genetic traits of these and the non-impaired individuals with vital neuronal cells being rescued from death and so providing a "cognitive reserve.” The inflammatory signals that initiate phagocytosis by microglia are driven by $\mathrm{A} \beta$ that involve the CD14 and TLR 2 and 4 signaling [22, 23, 48, 49], a pathway also used by microglia for bacterial LPS recognition [50]. Spontaneous loss-of-function mutation in the TLR 4 gene has been demonstrated to have an inhibitory effect on microglial cell activation. For example, presence of $A \beta$ in the microglia with mutated gene expression [49] demonstrated reduced secretion of inflammatory mediators such as interleukin-6 (IL-6) and tumor necrosis factor- $\alpha$ 
(TNF- $\alpha$ ) and nitric oxide. These findings further strengthen the cognitive reserve hypothesis in very old subjects in the presence of classical AD hallmark lesions.

Using an ex-vivo experimental model to examine the expression of pro-inflammatory cytokine profiles in whole blood from the healthy middle-aged offspring of patients affected by late-onset AD, van Exel et al. [10] reported higher levels of specific cytokines than were found in the siblings from non-AD parents. This finding also demonstrates that inflammation-related risk factors are present in currently healthy subjects who may have a genetic ‘susceptibility profile’ a phrase, coined by McGeer and McGeer [33] to late-onset AD. Despite the inheritance factors, the brain's response to inflammation is slow as supported by animal models of AD [51]. Currently, the greater accumulation of $\mathrm{A} \beta$ deposits in late-onset $\mathrm{AD}$ is considered to be the result of defects in the clearance system [52]. Therefore, the pertinent question would be, "what initially triggers $\mathrm{A} \beta_{40 / 42}$ release in patients with late-onset $\mathrm{AD?}$ ?

Infections are common in elderly individuals and are the main cause of death in a majority of neurodegenerative conditions. One hypothesis is that the elderly, per se, are immunocompromised and this correlates with their susceptibility to an increased incidence of infection [53, 54]. Recurrent bacteremia from common infections in the elderly, due to, for example, chronic periodontitis [55, 56], intra-abdominal [57], and urinary tract infections [58], will contribute to systemic circulation infections. In addition, chronic periodontitis demonstrates a promising link that encompasses environmental influences, susceptibility profiles, infectious agents, and a multitude of host's factors that affect its episodic re-occurrence [59]. Numerous studies show that tooth loss due to PD to correlate with cognitive impairment in AD [60-63]. Further studies have demonstrated systemically derived immune components such as antibodies to the periodontal pathogens circulating in the blood plasma of AD subjects [64]. In addition, AD 
patients with antibodies to the periodontal pathogens in their blood have displayed inflammatory mediators (cytokines) in the systemic circulation [64]. As Holmes et al. [9] suggest, these cytokines and those from alternative sources in the peripheral circulation have the potential to reach the brain parenchyma, and subsequently prime microglia to mount a local immune response with appropriate stimuli, and impair memory.

An alternative hypothesis for the role of $\mathrm{A} \beta$ in subclinical and/or clinical $\mathrm{AD}$ individuals is that $\mathrm{A} \beta$ is acting as an antimicrobial peptide [65] to counteract infections by functioning as part of the early innate immune defense mechanisms that mediate innate and adaptive immune responses [66]. Traditionally, antimicrobial peptides act as look-outs for invading microorganisms to maintain the balance between commensals. The main target for antimicrobial peptides is the pathogen cell membrane, as most antimicrobial peptides are cationic [67]. Antimicrobial peptides undergo electrostatic interactions with negatively charged molecules to penetrate bacterial cell walls, including anionic lipids and LPS [67]. They then invade the lipid bilayer, creating trans-membrane pores through which leakage of ions and metabolites, cytoplasmic components, dissipation of electrical potentials, and cell death of microbes takes place [68]. This hypothesis suggests the involvement of a pathogenic precursor in the initiation of $A \beta$ release before inflammation becomes detectable in the presence of this hallmark. We support this hypothesis and propose a suite of susceptibility traits and immunosuppressive (stressed or rundown) episodes during life that give way to chronic bacterial infections. These bacterial elements in the individuals with susceptibility profiles may trigger release of $\mathrm{A} \beta$ to neutralize their effect. Over time $A \beta$ will accumulate in the brains of healthy but susceptible individuals and initiate neuroinflammation that may cross the threshold from subclinical to lateonset $\mathrm{AD}$. 
The etiological hypothesis suggests that viruses and bacteria and/or their virulence factors access the brain and thereby contribute to AD pathogenesis. A review by Holmes and Cotterell [69] provides a range of infective agents consistently being linked to AD. These include viruses such as Herpes simplex virus type I [70], Chlamydophila pneumoniae [71], Treponema spp.,[72] Borrelia burgdorferi [73], and more recently LPS from P. gingivalis [74], one of the key bacteria causing PD in humans.

\section{Age-Related Personal Hygiene Changes as Risk for Infections}

Advancing age is the greatest risk factor for all forms of AD. Some consequences of advancing age are a compromised immune system $[53,54]$ and a neglect of general and oral personal hygiene [61, 75, 76], and such conditions are associated with recurrent, chronic infections. Recurrent, chronic infections enhance systemic hyperinflammatory profile that may lead to confusion and other dementia-like clinical features [7-9] in which the exact structural/cellular changes taking place at the time remain unknown.

Several studies support deterioration in oral health with increasing age [77-80]. The exact reasons are poorly understood, but advancing age is likely to compromise the manual dexterity of senior citizens and this may make cleaning their teeth more difficult, or perhaps it is because as general health concerns and conditions increase with age, maintenance of oral health becomes a lower priority. The elderly are more likely to be on multiple medications, many of which, as a side effect, cause xerostomia and this will inevitably be a factor in deteriorating oral health [81]. Furthermore, if the elderly suffer from physical impairments, accessing the dentist may become more difficult. Elderly people resident in care institutions are, to a certain extent, dependent on the level of care within the establishment for the level of oral hygiene and dental health they 
receive. These factors were supported in a large-scale survey carried out in the US by Griffin et al. [79], which found that older age groups were more likely to be edentulous or have untreated dental disease and root caries. Those who were either residents in institutions or homebound had higher levels of untreated cavities, gingivitis (a marker of poor oral hygiene), and poorer overall oral health than the elderly living independently. The study shows that cost, lack of transportation, and limited mobility were key barriers to accessing dental care for nursing home residents [79]. Other groups of elderly that show higher untreated dental disease and lower levels of oral health are those from ethnic minorities and low-income families [79].

\section{Periodontal Disease}

PD is a polymicrobial inflammatory disease that has been estimated to affect $10-15 \%$ of the developed world population and is a major cause of tooth loss. The prevalence of PD increases with age, affecting around 50\% of people over the age of 55 years [82]. The disease affects tooth supporting tissues wherein the interaction of specific bacteria and the host's immune responses play a pivotal role [59]. The host's response to bacteria and their products is an important factor in determining the extent and severity of PD [83]. The acute bacterial challenges stimulate junctional transformed pocket epithelium to produce a broad range of inflammatory mediators to guard against gingival tissue damage. The inefficient clearance of subgingival pathogens by the innate immune system compromises the integrity of periodontal tissues and eventually results in the formation of periodontal pockets.

Periodontitis, involving specific bacteria coupled with the host's response, initiates an acute phase receptor-mediated cytokine production by epithelial cells and simultaneous neuropeptide release, resulting in vasodilation of local vessels. Chemokines mobilize neutrophils from blood 
vessels for migration to the area of bacterial invasion. Gingival bleeding, swelling, and redness together with the presence of neutrophils/macrophages within the inflamed gingivae indicate clinical signs of inflammation. The infection is both confined to, and subsequently cleared by, neutrophils and macrophages, or expands to include other cells and structures [84]. In the high susceptibility profile group of individuals, the acute phase responses fail to clear the infection, and chronic inflammatory lesions develop within a matter of weeks. The pathogenic consortium consisting of Porphyromonas gingivalis (P. gingivalis), Tannerella forsythia (T. forsythia), and Treponema denticola (T. denticola) appear to be the main organisms involved in the development of chronic PD [85, 86]. The subgingival sulcus serves as a niche enabling a cyclic chronic inflammatory process which in turn facilitates recurrent bacteremia following routine oral health regimes [55, 56, 87]. A number of inflammatory pathologies are said to develop in this way, including cardiovascular diseases [88, 89], rheumatoid arthritis [90-92], diabetes mellitus [93], and others as well as $\mathrm{AD}[60,61,64,72,74]$.

\section{Anatomical Relationship of Facial Nerves and the Blood Supply to the Brain}

The position of the oral cavity, serving the need for speech and food consumption, connects with the brain via series of nerves. Cranial nerve 1 (CN1) is the special sensory nerve for olfaction and contributes not only to our sense of smell but also to that of taste. CN1 has complex pathways that trigger visceral responses (salivation and nausea or accelerated peristalsis in the intestinal tract and increased gastric secretion) to various odors. Although CN1 is recognized and named as the olfactory nerve, the majority of the olfactory tract comprises of secondary, rather than primary sensory axons; thus it is really not a "nerve" but rather a bulb and tract. There is a physical connection between the oral and nasal cavity, extending onto the 
superior nasal conchae and nasal septum and contains neurosensory cells and olfactory glands, which keep the mucosa moist and in which the dissolution of inhaled scents (aromatic molecules) occurs. The peripheral processes of the primary sensory neurons in the epithelium perform as sensory receptors and transmit sensation centrally, which congregate into around 20 bundles, which, in turn, pass through foramina of the cribiform plate of the ethmoid bone. The cribiform plate of the ethmoid bone is the porous barrier between the nasal passages and the brain itself. Once they have passed through the cribiform plate, the central processes synapse on the secondary sensory neurons in the olfactory bulb itself, which houses the nerve cell bodies. Behind this area is the olfactory tract and trigone; the nerve cell bodies travel to the three olfactory areas, located in the anterior part of the entorhinal cortex area, encompassing the hippocampal gyrus and all ultimately lead to the hippocampus [94].

Cranial nerve V (CN V) or the trigeminal nerve, arising from the mid-lateral surface for the pons, is primarily a general sensory nerve with smaller motor component. There are three divisions of the $\mathrm{CN} V$ which are ophthalmic $\left(\mathrm{V}\right.$ I), maxillary $\left(\mathrm{V}_{2}\right)$ and mandibular $\left(\mathrm{V}_{3}\right)$ where, the motor root of CN V travels with the mandibular branch. The ophthalmic division (V I) exits the neurocranium through the supraorbital fissure, the maxillary division $\left(\mathrm{V}_{2}\right)$ through the foramen rotundum in the sphenoid bone and the mandibular $\left(\mathrm{V}_{3}\right)$ branch through the sphenoid's foramen ovale. CN V is a general sensory nerve to the scalp, face, nasal and oral cavities (including the teeth and tongue), and brachial motor nerve to the muscles of mastication (temporalis, masseter, medial pterygoid, and lateral pterygoid), tensor tympani, tensor (veli) palitini, mylohyoid, and the anterior belly of the digastric. When dental or periodontal therapy is performed using local anesthesia (e.g., novocaine, xylocaine), the drug is injected into the oral mucosa covering the bony foramina where the sensory branches of the CN V exit into the oral 
cavity. For the maxillary dental arcade, the injection is aimed toward the pterygopalatine ganglion; for the mandibular teeth, this is directed toward the mandibular foramen. In the case of the pterygopalatine ganglion, this supplies sensation via branches of $V_{2}$ from the nasal cavity, plate, nasopharynx, and maxillary teeth. The lingual and inferior alveolar nerve branches carry sensation from the entirety of the lower jaw, mandibular teeth, gums, and anterior two thirds of the tongue as shown in Figure 1. As with most nerves, the branches of the trigeminal nerve are accompanied by veins and arteries along the peripheries of their pathways [94].

The olfactory and the trigeminal nerve(s) pathways are also exploited by periodontal pathogens as a means of bypassing the BBB for direct entry into the CNS [72, 95, 96], an observation supported by studies in immunosuppressed animal models using T. denticola [97]. The animal model study allows some insight into the virulence of the organism and the host's immune defenses as being important for this occurrence.

The systemic route as an alternative mode of bacterial entry into the brain is favored due to bacteremia as mentioned earlier, association of periodontal pathogens with atherosclerotic lesions and in particular P. gingivalis having the ability to adhere to erythrocytes for innate immune evasion $[87,98,99]$ as well as gaining advantage for transportation to remote body organs [99].

The brain is supplied by three paired blood vessels: the right and left internal carotid arteries, arising from the common carotid artery at the base of the neck. It has three divisions that enter the cranium, anteriorly through the carotid canal of the temporal bone and through foramen lacerum in the middle cranial fossa. The vertebral arteries arise from the subclavian arteries, bilaterally and both enter the cranium via the foramen magnum. The vertebral and internal carotid arteries unite on the base of the brain at the Circle of Willis, via a series of 
interconnecting smaller arteries. The basilar artery is created when the vertebral arteries join. The Circle of Willis itself is composed of the posterior cerebral, posterior communicating, internal carotid, anterior cerebral and anterior communicating arteries; all these arteries branch to supply the brain itself [94] including the circumventricular organ regions where bacteria and bacterial products access the brain.

\section{The Association between Periodontal Disease and Alzheimer's Disease}

Longitudinal studies have shown that people with PD who progressed to the development of AD had poorer oral health [61, 76, 79, 100-102]. Does poor oral health always mean that the pathogens will disseminate to the brain even in AD patients? Both our unpublished data from controlled experiments using animal models, and that of Foschi et al. [97], indicate that the presence and motility of the low virulence strains of periodontal pathogens may not be sufficient for them to access the brain. However, animal models of oral diseases (periodontitis and endodontic) may require an adjustment for the optimization of dosage and/or duration of infection to allow for bacteria to translocate to the brain. Our unpublished data demonstrates that $P$. gingivalis (FDC381) accessed the brain of ApoE ${ }^{\text {null }}$ mice following an oral infection while $P$. gingivalis (ATCC 33277) failed, even in SCID mice mono and poly infections [97]. It therefore appears that the greater virulence of $P$. gingivalis (FDC 381) due to having acquired fimbriae, likely allowed its adherence to erythrocytes for innate immune evasion, a process that has gained the bacterium an advantage for dissemination [99], to the brain [Poole et al. unpublished results]. When the duration of active infection supersedes the virulence of the bacteria, there remains a high possibility that the host harboring the periodontal pathogens will demonstrate these bacteria disseminating to the brain. Immunocompromised status seen in AD patients will also enhance the 
infection process. This begs the question as to what causes some individuals to harbor periodontal bacteria rather than other species? Could there be as yet unknown genetic factors/inflammatory traits, lifestyle driven environmental stressors?

However, it should be noted that patients suffering from AD cognitive impairment are poor at managing their personal oral health. In addition, a caregiver or dentist may face a marked decrease in co-operation from the $\mathrm{AD}$ patient, making management of oral health more challenging. With patients having increased cognitive impairment, such as reduced adaptation to change, dentists often choose not to carry out the dental treatment that would give optimal oral health. For example, patients with AD may well be unable to cope with extensive, potentially unpleasant dental procedures, leaving them with fewer teeth, which could have a detrimental impact on their eating ability.

Nutritional deficiencies are documented in the elderly as well as in the dementia subjects, especially with regard to lessened intake of B-vitamins and folic acid in the diet. The marker that indicates these deficiencies also correlates with cognitive decline, but as consequence of disease rather than a cause [103]. The mechanism of cognitive decline is suggested via synaptic dysfunction, which is one of the earliest structural defects associated with decline in memory [19]. Diet provides the essential B-vitamins, phospholipids, and other micronutrients, which are required for the formation of new synapses [104].

\section{Epidemiological Evidence for the Association between Chronic Periodontitis and}

\section{Alzheimer's Disease}

Clinical/epidemiological studies so far, all agree on loss of teeth leading to poor memory [6063]. Further studies have examined possible inflammatory biomarkers in an attempt to link 
and/or to find new diagnostic makers of AD. Others have, however, used more specific measures including IgG levels to P. gingivalis and other specific periodontal pathogens [64, 105]. A study by Sparks Stein et al. [105] used cohort methodology analyzing levels of serum antibodies to periodontal disease. At the start of the study period, all participants were cognitively intact, but higher levels of serum antibodies to periodontal pathogens at baseline led to some individuals developing $\mathrm{AD}$ [105]. As baseline measures were taken years before diagnosis of $\mathrm{AD}$, the elevation in serum antibodies cannot be attributed to secondary effects of AD (for example, poor oral hygiene). Although clinical measurements of oral health were not taken in the Sparks Stein et al. [105] investigation, periodontal bacterial species are generally accepted as being specific enough to PD and assessing serum antibody levels to these pathogens may prove to be a true indicator of $\mathrm{PD}$ in $\mathrm{AD}$ patients.

\section{Possible Confounders}

Several environmental, epidemiological, and risk factors show similar trends and patterns in both $\mathrm{PD}$ and $\mathrm{AD}$. Whether or not this is coincidental or arises through shared developmental pathways remains unclear. The impact of these associations is the potential for these factors to act as confounders, influencing the true relationship between PD and AD.

The incidence of both PD and AD increases with age; this has already been mentioned in previous sections. Gender related trends exist between AD and periodontal disease. The incidence of $\mathrm{AD}$ has been shown to be higher in women after 85 years of age. This is thought to be due to the protective effect of pre-menopause estrogen [106]. Men, however, have been shown to have a greater incidence of PD (up to 50\%) than women overall [107]. Interestingly, this study also showed that men with PD also had increased incidence of coronary artery disease, 
suggesting fewer men than women survive to old age. Physical activity has been shown to have a positive effect on cognitive function and those aged 70-79 years with high levels of activity show lower levels of inflammatory markers such as IL-6 and C-reactive protein [106]. Likewise obesity has shown similar trends, in that those who are obese suffer a greater incidence of AD. Although physical activity and the incidence of PD have not been investigated directly, many studies have shown an indirect relationship, highlighting a greater incidence of PD with obesity and diabetes $[107,108]$. It has been suggested that obesity may be the second highest risk factor for PD after smoking [109]. The underlying mechanism for this association is thought to be related to proinflammatory cytokines, including IL-6 and C-reactive protein that are released by adipose tissue, along with hormones adipokines or adipocytokines. With the increasing levels of evidence supporting inflammatory processes in $\mathrm{AD}$ development, it is possible that the relationship between AD and obesity may follow similar mechanisms [109]. Poorer general health may be associated with PD due to a compromising immune system and therefore, the ability of the host to defend against periodontal bacterial infections.

It is generally accepted that smoking is the major risk factor in periodontal disease. Smokers are 2-7 times more likely to present with PD than non-smokers and this is unrelated to oral hygiene. Disease progression is more rapid and response to treatment is poorer [109]. Smoking is thought to affect neutrophil function, reducing the host's ability to eliminate periodontal pathogens. Smokers with PD have distinct patterns of pathogenic microbial profile than nonsmokers with PD [110-112]. Smoking is also thought to lead to release of reactive oxidative species and oxidative stress mediated tissue damage. Inflammatory cytokine and chemokine expression in smokers compared to non-smokers show many differences reflecting the 
immunosuppressant effect of smoking, which may contribute to an enhanced susceptibility to periodontitis [113].

The relationship between smoking and $\mathrm{AD}$ is less clear; with some studies suggesting smoking has a beneficial effect due to nicotine treatment improving cognitive performance in age associated memory impairment [114], while others suggesting that smoking increase the risk of $\mathrm{AD}$. In the proposed theory, an increased risk of $\mathrm{AD}$ is similarly related to the factors causing periodontal disease, whereby smoking increases free radical generation leading to high oxidative stress, or affects the inflammatory immune system leading to phagocyte activation and further oxidative damage.

PD would appear to have an increased prevalence in both ethnic minority groups and lower socioeconomic status. This has been attributed to a complex combination of social, psychological, and structural factors including nutrition, oral hygiene, healthcare utilization, and access to care. It is thought that having lack of resources to pay for care, not having a regular source of care, or availability of transportation to healthcare centers contribute to these trends [115-117].

The relationship between race and socioeconomic status and AD appears more complex. Meta-analysis assessing the relationship between education level and AD showed that overall those with low or no education were more likely to develop AD, but this was not shown in all studies. This relationship was stronger in developed, compared to developing countries possibly due to life-expectancy being shorter in developing countries. Individuals with less education appear to have lower cognitive function compared to those with higher education levels. Education-dementia relationship appears to vary according to age, gender, and race/ethnicity and the suggestion is that the relationship ties in with a person's life events beginning prior to and 
carrying on beyond years of formal education [118]. These epidemiological trends associated with both PD and AD demonstrates the importance for excluding the impact of confounders when investigating a true relationship between PD and AD.

\section{Genetic Risk Factors for Late-Onset Alzheimer's Disease and Periodontitis}

The apolipoprotein E (ApoE) gene is a known genetic risk factor associated with late-onset $\mathrm{AD}$, and more recent investigations suggest some further genetic risk factor associations with innate immune molecules and inflammatory traits in late-onset $\operatorname{AD}[10,15,16]$. In particular, cytokine-related genes appear to be involved in the susceptibility to inflammation in late-onset $\mathrm{AD}[10,12,33]$ as well as in PD [119-121].

As the immune system plays an important role in PD pathogenesis [59], it is thought that PD itself may have genetic associations. Polymorphisms in IL- $\alpha$, IL-1 $\beta$, IL-6, and TNF- $\alpha$ genotype are reported for periodontitis [119-121] and similarly IL-1 $\alpha$, IL-1 $\beta$, IL-6, TNF- $\alpha, \alpha 2-$ macroglobulin, and $\alpha 1$-antichymotrypsin are all upregulated in $\mathrm{AD}[12,33]$ suggesting commonalities between susceptibility profiles in these two disease conditions. As mentioned earlier, offspring of parents with AD have higher inflammatory cytokines in their blood than those who are descendants of non-AD parents [10]. Similarly, parents with poor oral health tend to have children with poor oral health; however, it is difficult to conclude that the poor oral health trait is a result of the genetic makeup of the individual and not simply an environmental influence [122].

\section{Stress Environmental and Genetic Factors}

Stress: In health 
Acute stressors in the environment, such as facing a dangerous situation, activate physiological systems designed to enhance self-preservation [123]. These include the sympathetic-adrenal-medullary and the more slowly responding hypothalamus pituitary adrenal (HPA) axis. This response prepares the body to cope with threat [124]. The two response systems work by increasing certain hormones, such as adrenaline and cortisol. These, in turn, act on the biological functioning of the individual, such as increased heart rate, inhibition of the digestive system, or increased glucose supply to the muscles. Although the physiological changes enhance our ability to mount a physical response to threat, the associated neurochemical changes can lead to cognitive failures, which may present as dementia-like even within a cognitively normal population. For example, elevations in cortisol as a result of activation of the HPA axis can lead to impairments in attention [125], working memory and inhibitory control [126], and declarative memory [127]. Cognitive impairments due to acute stressors are reversible. Further acute stress responses may actually have some benefits for health with enhancements in immune function being reported [128]. However, when short-term beneficial adaptations designed to maintain homeostasis during acutely stressful events become excessive or prolonged, problems can occur [129].

\section{Stress: Periodontal disease}

Psychological stress may affect periodontal disease. Such stressors can lead to a change in health behaviors, which in turn may lead to associated increased risk of PD. For example, poorer oral hygiene coupled with increased smoking [130] and alcohol intake [131]; visiting the dentist less regularly, and eating less healthily with higher fat and sugar diets [132] encourage bacterial growth and worsen periodontal status. 
Stress impairs the balance between pro- and anti-inflammatory responses. Alterations in inflammatory polymorphic gene function, in particular of IL-1 and IL-6 (119-121), will affect polymorphonuclear leukocyte chemotaxis. The net effect will be reduced lymphocyte proliferation and this may increase the vulnerability of periodontal tissue to microorganisms leading to further tissue destruction [133]. Inhibition of $\mathrm{T}$ cell responses by glucocorticoids appears to explain, in part, susceptibility to PD and pro-inflammatory cytokines are potent activators of the HPA axis [134, 135]. Patients with PD who are stressed show increased IL-6 and IL-1 $\beta$ levels in gingival crevicular fluid [133]. Results of several studies were reviewed and demonstrated a correlation between psychological stress and salivary and blood stress markers relating to inflammatory response and progression of PD [134]. However, a cause and effect relationship has not, so far been found, therefore stress is considered a risk factor for PD rather than a cause.

Stress: Alzheimer's disease

High levels of environmental stressors could lead to impairments in cognitive processes, which are important for maintaining oral hygiene. For example, acute and chronic activation of the HPA axis can lead to elevated basal cortisol levels. High levels of circulating cortisol causes hippocampal damage and so impair hippocampus-dependent memory processes [125]. In a cognitively intact elderly population, higher cortisol levels were indicative of impairments of declarative memory and executive functioning [135], both of which are needed to maintain good oral hygiene.

The hippocampus is the area of pathology in $\mathrm{AD}$ and is vulnerable to effects of stress and trauma [136]. Chronic stress can impair immune responses and so compromise the body's ability 
to resist disease [137]. The brain attempts to compensate cellular stress, by regulatory mechanisms, involving upregulation of heat shock proteins [138]. Loss of heat shock proteins, in vitro, was shown to contribute to accumulation of hyperphosphorylated tau, a component of NFTs, and a hallmark of AD pathology [139]. In addition, stress activated protein kinases, for example, mitogen-activated protein kinase 38 and the c-jun N-terminal kinases are activated in AD [140,141]. These two stress pathways can also be activated by oxidative stress [142, 143], a common denominator of environmental, pathological, and habitual factors.

\section{Critical Remarks about the Present State of the Research to Relationship between Alzheimer's Disease and Chronic Periodontitis}

Clinical observational studies thus far all correlate with loss of teeth leading to poor memory. However, direct evidence is lacking to support a causal association between periodontal bacteria and progression of AD. The clinical studies have been performed on elderly cohorts where overlapping features of the aging process, such as deposition of $A \beta$ in the brain is likely to have already begun. When assessing periodontal status clinically, levels of caries may not have been accounted for. Oral hygiene studies were based on retrospective questionnaire surveys, which may introduce selection bias depending on the response rate. People who are motivated to complete questionnaires may be more likely to visit the dentist than those who do not. Genetic factors have not given importance in some of the studies. Both the Riviere et al. [72] and the Poole et al. [74] studies lacked information concerning the periodontal status of the cases analyzed.

\section{Future Research}


How PD contributes to impaired memory remains intriguing and future studies should be directed towards addressing these mechanisms. There is paucity of information relating to the exact risk factor(s) for the development of deteriorating memory from missing teeth in the prodromal phase of AD. Are these factors downstream of co-morbidities such as diabetes affecting periodontal status of the individual? Or common susceptibility profiles play a key role in loss or gain of function in future generations of $\mathrm{AD}$ parents. Further evidence to support an association between $\mathrm{PD}$ and $\mathrm{AD}$, research would need to demonstrate that the inflammatory and immunological responses that the bacteria and their virulence factors induce may subsequently lead to the onset of AD. Perhaps associations between parents with AD and their children at a much younger age should be monitored for oral health as that should eliminate any overlapping confounders that may be masking the true links in these two conditions.

This review clearly indicates significant gaps in our current understanding of the causal association of pathogens (spirochetes, bacteria, viruses) in a slowly progressive and debilitating disease such as AD. Although various types of neurotropic spirochetes including oral (Treponema spp) and non-oral spirochetes (B. burgdorferi) have been detected directly in association with the pathological hallmarks of $\mathrm{AD}$ [73] but, a causal relationship has not been tested in animal models. To the best of our knowledge, there is no single in vivo animal model study that has examined the role of periodontal bacteria during chronic infection (9-12 months of exposure times) to study the sequence of neuropathological events associated with the development of AD pathology. Even though infectious agents have been implicated in relation to AD hallmark pathology for over a century ago, several clinical and molecular studies strongly support an association between PD and AD. However, to date, there is a paucity of reports 
supporting a causative relationship between periodontal pathogens and $\mathrm{AD}$ cases and in vivo transgenic mice.

\section{Acknowledgments}

The authors thank the project support to LK by 1R01 DE020820-01A1, NIH/NIDCR, USA. The work described in this manuscript was fully funded by the University of Central Lancashire. SKS is a privileged recipient of the 2011, Don Claugher Bursary prize which was awarded by the Committee of the Society of Electron Microscope Technology (http://www.semt.org.uk).

Authors’ disclosures available online (http://www.j-alz.com/disclosures/view.php?id=2275). 


\section{References}

[1] Winblad B (2002) Socio-economic perspectives of dementia and cost effectiveness of treatment. 7th International Geneva/Springfield Symposium on Advances in Alzheimer Therapy, April 3-6, Geneva, Switzerland.

[2] Evans DA (1990) Estimated prevalence of Alzheimer's disease in the United States. Milbank Q 68, 267-289.

[3] Small GW, Donohue JA, Brooks RL (1998) An economic evaluation of donepezil in the treatment of Alzheimer's disease. Clin Ther 20, 839-850.

[4] Stewart WF, Kawas C, Corrada M, Metter EJ (1997) Risk of Alzheimer's disease and duration of NSAID use. Neurol 48, 626-632.

[5] Anthony JC, Breitner JC, Zandi PP, Meyer MR, Jurasova I, Norton MC, Stone SV(2000) Reduced prevalence of AD in users of NSAIDs and $\mathrm{H} 2$ receptor antagonists: the Cache County study. Neurol 54, 2066-2071.

[6] Broe GA, Grayson DA, Creasey HM, Waite LM, Casey BJ, Bennett HP, Brooks WS, Halliday GM. (2000) Anti-inflammatory drugs protect against Alzheimer disease at low doses. Arch Neurol 57, 1586-1591.

[7] Dunn N, Mullee M, Perry VH, Holmes C (2005) Association between dementia and infectious disease: evidence from a case-control study. Alzheimer Dis Assoc Disord 19(2), 91-94.

[8] Holmes C, El-Okl M, Williams AL, Cunningham C, Wilcockson D, Perry VH (2003) Systemic infection, interleukin $1 \beta$ and cognitive decline in Alzheimer's disease. J Neurol Neurosurg Psychiatry 74, 788-789.

[9] Holmes C, Cunningham C, Zotova E, Woolford J, Dean C, Kerr S, Culliford D, Perry VH (2009) Systemic inflammation and disease progression in Alzheimer's disease. Neurology 73, 
768-774.

[10] van Exel E, Eikelenboom P, Comijis H, Frolich M, Amit JH, Stek ML, Scheltens P, Eefsting JE, Westendorp RG (2009) Vascular factors and markers of inflammation in offspring with a parental history of late onset Alzheimer disease. Arch Gen Psychiatry 66, 1263-1270.

[11] Eikelenboom P, Veerhuis R, van Exel E, Hoozemans JJM, Rozemuller AJM, van Gool WA (2011) The early involvement of the innate immunity in the pathogenesis of late-onset Alzheimer’s disease: Neuropathological, epidemiological and genetic evidence. Curr Alzheimer Res 8, 142-150.

[12] Nicoll JAR, Mrak RE, Graham DI, Stewart J, Wilcock G, MacGowan S, et al. (2000) Association of interleukin-1 gene polymorphisms with Alzheimer's disease. Ann Neurol 47, 365368.

[13] Eikelenboom P, Rozemuller JM, Kraal G, Stam FC, McBride PA, Bruce ME, Fraser H (1991) Cerebral amyloid plaques in Alzheimer's disease but not in scrapie-affected mice are closely associated with a local inflammatory process. Virchows Arch B (Cell Pathol) 60, 329336.

[14] Akiyama H, Barger S, Barnum S, Bradt B et al., (2000) Inflammation and Alzheimer’s disease. Neurobiol Aging 21, 383-421.

[15] Lambert JC, Heath S, Even G, Campion D, Sleegers K, Hiltunen M, Combarros O, Zelenika D, Bullido MJ, Tavernier B, Letenneur L, Bettens K, Berr C, Pasquier F, Fiévet N, BarbergerGateau P, Engelborghs S, De Deyn P, Mateo I, Franck A, Helisalmi S, Porcellini E, Hanon O; European Alzheimer's Disease Initiative Investigators, de Pancorbo MM, Lendon C, Dufouil C, Jaillard C, Leveillard T, Alvarez V, Bosco P, Mancuso M, Panza F, Nacmias B, Bossù P, Piccardi P, Annoni G, Seripa D, Galimberti D, Hannequin D, Licastro F, Soininen H, Ritchie K, 
Blanché H, Dartigues JF, Tzourio C, Gut I, Van Broeckhoven C, Alpérovitch A, Lathrop M, Amouyel P (2009) Genome-wide association study identifies variants at CLU and CR1 associated with Alzheimer's disease. Nat Genet 41, 1094-1099.

[16] Harold D, Abraham R, Hollingworth P, Sims R, Gerrish A, Hamshere ML, Pahwa JS, Moskvina V, Dowzell K, Williams A, Jones N, Thomas C, Stretton A, Morgan AR, Lovestone S, Powell J, Proitsi P, Lupton MK, Brayne C, Rubinsztein DC, Gill M, Lawlor B, Lynch A, Morgan K, Brown KS, Passmore PA, Craig D, McGuinness B, Todd S, Holmes C, Mann D, Smith AD, Love S, Kehoe PG, Hardy J, Mead S, Fox N, Rossor M, Collinge J, Maier W, Jessen F, Schürmann B, Heun R, van den Bussche H, Heuser I, Kornhuber J, Wiltfang J, Dichgans M, Frölich L, Hampel H, Hüll M, Rujescu D, Goate AM, Kauwe JS, Cruchaga C, Nowotny P, Morris JC, Mayo K, Sleegers K, Bettens K, Engelborghs S, De Deyn PP, Van Broeckhoven C, Livingston G, Bass NJ, Gurling H, McQuillin A, Gwilliam R, Deloukas P, Al-Chalabi A, Shaw CE, Tsolaki M, Singleton AB, Guerreiro R, Mühleisen TW, Nöthen MM, Moebus S, Jöckel KH, Klopp N, Wichmann HE, Carrasquillo MM, Pankratz VS, Younkin SG, Holmans PA, O'Donovan M, Owen MJ, Williams J (2009) Genome-wide association study identifies variants at CLU and PICALM associated with Alzheimer's disease. Nat Genet 41, 1088-1093.

[17] Braak H, Braak E (1995) Staging of Alzheimer's disease-related neurofibrillary changes. Neurobiol Aging 16, 271-278.

[18] Alzheimer A (1907) Ueber eine eigenartige Erkankung der Hirnrinde. Allgemein Zeitschrift Psychiatrie 64, 146-148.

[19] Terry RD (1991) Physical basis of cognitive alterations in Alzheimer’s disease: synapse loss is the major correlate of cognitive impairment. Ann Neurol 30, 572-580.

[20] Iqbal K, Grundke-Iqbal I (1991) Ubiquitination and abnormal phosphorylation of paired 
helical filaments in Alzheimer's disease. Mol Neurobiol 5, 399-410.

[21] Brion JP, Hanger DP, Bruce MT, Couck AM, Flament-Durand J, Anderton BH (1991) Tau in Alzheimer neurofibrillary tangles. $\mathrm{N}$ - and C-terminal regions are differentially associated with paired helical filaments and the location of a putative abnormal phosphorylation site. Biochem $J$ 273, 127-133.

[22] Kopec KK, Carroll RT (1998) Alzheimer's beta-amyloid peptide 1-42 induces a phagocytic response in murine microglia. $J$ Neurochem 71, 2123-2131.

[23] Reed-Geaghan EG, Savage JC, Hise AG, Landreth GE (2009) CD14 and toll-like receptors 2 and 4 are required for fibrillar A $\{$ beta\}-stimulated microglial activation. $J$ Neurosci 29, 1198211992.

[24] Duckworth WC, Bennett RG, Hamel FG (1998) Insulin degradation: progress and potential. Endocr Rev 19, 608-624.

[25] Farris W, Mansourian S, Chang Y, Lindsley L, Eckman EA, Frosch MP, Eckman CB, Tanzi RE, Selkoe DJ, Guenette S (2003)Insulin-degrading enzyme regulates the levels of insulin, amyloid beta-protein, and the beta-amyloid precursor protein intracellular domain in vivo. Proc Natl Acad Sci U S A 100, 4162-4167.

[26] Biessels GJ, Kappelle LJ (2005) Increased risk of Alzheimer’s disease in type II diabetes: insulin resistance of the brain or insulin-induced amyloid pathology? Biochem Soc Trans 33, 1041-1044.

[27] Lester-Coll N, Rivera EJ, Soscia SJ, Doiron K, Wands JR, de la Monte SM (2006) Intracerebral streptozotocin model of type 3 diabetes: relevance to sporadic Alzheimer’s disease. J Alzheimers Dis 9, 13-33.

[28] Labak M, Foniok T, Kirk D, Rushforth D, Tomanek B, Jasinski A, Grieb P (2010) 
Metabolic changes in the rat brain following intracerebriventricular injections of streptozotocin: a model of sporadic Alzheimer’s disease. Acta Neurochir Suppl 106, 177-181.

[29] Yanker BA, Duffy LK, Kirschner DA (1990) Neurotrophic and neurotoxic effects of amyloid beta protein: reversal by tachykinin neuropeptides. Science 250, 279-282.

[30] Deshpande A, Mina E, Glabe C, Busciglio J (2006) Different conformations of amyloid beta induces neurotoxicity by distinct mechanisms in human cortical neurons. J Neurosci 26, 60116018.

[31] Banati RB, Myers R, Kreutzberg (1997) GW PK ('peripheral benzodiazepine’)-binding sites in the CNS indicate early and discrete brain lesions: microautoradiographic detection of [3H]pk11195 binding to activated microglia. J Neurocytol 26, 77-82.

[32] Banati RB (2002) Visualising microglial activation in vivo. Glia 40, 206-217.

[33] McGeer PL, McGeer EG (2001) Polymorphisms in inflammatory genes and the risk of Alzheimer disease. Arch Neurol 58, 1790-1792.

[34] Schwab C, McGeer PL (2008) Inflammatory aspects of Alzheimer disease and other neurodegenerative disorders. J Alzheimers Dis 13, 359-369.

[35] Oldfield BJ, Mckinley MJ (1995) Circumventricular organs, In The Rat Nervous System, Paxinos G, ed. Academic Press, San Diego, pp. 391-403.

[36] Lacroix S, Feinstein D, Rivest S (1998) The bacterial endotoxin lipopolysaccharide has the ability to target the brain in upregulating its membrane CD14 receptor within specific cellular populations. Brain Pathol 8, 625-640.

[37] Ross TM, Martinez PM, Renner JC, Thorne RG, Hanson LR, Frey WH 2nd (2004) Intranasal administration of interferon beta bypasses the blood-brain barrier to target the central nervous system and cervical lymph nodes: a non-invasive treatment strategy for multiple 
sclerosis. J Neuroimmunol 151, 66-77.

[38] Rivest S (2009) Regulation of innate immune responses in the brain. Nat Rev Immunol 9, 429-439.

[39] Morgan BP, Gasque P (1996) Expression of complement in the brain: role in health and disease. Immunol Today 17, 461-466.

[40] Freeman MR (2006) Sculpting the nervous system: glial control of neuronal development. Curr Opin Neurobiol 16, 119-125.

[41] Perry VH, Nicoll JA, Holmes C (2010) Microglia in neurodegenerative disease. Nat Rev Neurol 6,193-201.

[42] Hitt R, Young-Xu Y, Silver M, Perls T (1999) Centenarians: the older you get the healthier you've been. Lancet 354, 652.

[43] Kliegel M, Moor C, Rott C (2004) "Cognitive status and development in the oldest old: a longitudinal analysis from the Heidelberg Centenarian study”. Arch Gerontol Geriatr 39, 143156.

[44] Perls T (2004) Centenarians who avoid dementia. Trends Neurosci 27, 633-636.

[45] Imhof A, Kövari E, von Gunten A, Gold G, Rivara CB, Herrmann FR, Hof PR, Bouras C, Giannakopoulos P (2007) Morphological substrates of cognitive decline in nonagenarians and centenarians: A new paradigm? J Neurol Sci 257, 72-79.

[46] Cagin A, Brooks DJ, Kennedy AM, Gunn RN, Myers R, Turkheimer FE, Jones T, Banati RB (2001) In-vivo measurement of microglia in dementia. Lancet 358, 461-467.

[47] Okello A, Edison P, Archer HA, Turkheimer FE, Kennedy J, Bullock R, Walker Z, Kennedy A, Fox N, Rossor M, Brooks DJ (2009) Microglial activation and amyloid deposition in mild cognitive impairment: a PET study. Neurology 72, 56-62. 
[48] Fassbender K, Walter S, Kühl S, Landmann R, Ishii K, Bertsch T, Stalder AK, Muehlhauser F, Liu Y, Ulmer AJ, Rivest S, Lentschat A, Gulbins E, Jucker M, Staufenbiel M, Brechtel K, Walter J, Multhaup G, Penke B, Adachi Y, Hartmann T, Beyreuther K (2004) The LPS receptor (CD14) links innate immunity with Alzheimer’s disease FASEB J 18, 203-205.

[49] Walter S1, Letiembre M, Liu Y, Heine H, Penke B, Hao W, Bode B, Manietta N, Walter J, Schulz-Schuffer W, Fassbender K (2007) Role of Toll-like receptor 4 in neuroinflammation in Alzheimer’s disease. Cell Physiol Biochem 20, 947-956.

[50] Wright SD, Ramos RA, Tobias PS, Ulevitch RJ, Mathison JC (1990) CD14, a receptor for complexes of lipopolysaccharide (LPS) and LPS binding protein. Science 12, 56-63.

[51] Spires TL, Hayman BT (2005) Transgenic models of Alzheimer’s disease: Learning from Animals. NeuroRx 2, 423-437.

[52] Zlokovic BV, Frangione B (2003) Transport clearance hypothesis for A $\beta$ metabolism and Alzheimer's disease. In A $\beta$ Metabolism and Alzheimer's Disease. Saido TC, ed. Landes Bioscience, Georgetown, Texas, 117-125.

[53] Pawelec G (1999) Immunosenescence: impact in the young as well as the old? Mech Ageing Dev 108, 1-7.

[54] Targonski PV, Jacobson RM, Poland GA (2007) Immunosenescence: role and measurement in influenza vaccine response among the elderly. Vaccine 25, 3066-3069.

[55] Forner L, Larsen T, Kilian M, Holmstrup P (2006) Incidence of bacteremia after chewing, tooth brushing, and scaling in individuals with periodontal inflammation. J Clin Periodontol 33, 401-407.

[56] Lockhart PB, Brennan MT, Sasser HC, Fox PC, Paster BJ, Bahrani-Mougeot FK (2008) bacteremia associated with tooth brushing and dental extraction. Circulation 117, 3118-3125. 
[57] Norman DC, Yoshikawa TT (1983) Intraabdominal infections in the elderly. J Am Geriatr Soc 31, 677-684.

[58] De Vecchi E, Sitia S, Romanò CL, Ricci C, Mattina R, Drago L (2013) Aetiology and antibiotic resistance patterns of urinary tract infections in the elderly: a six months study. $J$ Med Microbiol 62, 859-863.

[59] Haffajee AD, Socransky SS, Dzink JL, Taubman MA, Ebersole JL, Smith DJ (1988) Clinical, microbiological and immunological features of subjects with destructive periodontal diseases. J Clin Periodontol 15, 240-246.

[60] Gatz M, Mortimer JA, Fratiglioni L, Johansson B, Berg S, Reynolds CA, Pedersen NL (2006) Potentially modifiable risk factors for dementia in identical twins. Alzheimers Dement 2, 110-117.

[61] Stein PS, Desrosiers M, Donegan SJ, Yepes JF, Kryscio RJ (2007) Tooth loss, dementia and neuropathy in the Nun study. J Am Dent Assoc 138, 1314-1322.

[62] Stewart R, Sabbah W, Tsakos G, D’Aiuto F, Watt RG (2008) Oral health and cognitive function in the Third National Health and Nutrition Examination Survey (NHANES III). Psychosom Med 70, 936-941.

[63] Noble JM, Borrell LN, Papapnou PN, Elkind MSV, Scarmeas N, Wright CB (2009) Periodontitis is associated with cognitive impairment among older adults: analysis of NHANESIII. J Neurol Neurosurg Psychiat 80, 1206-1211.

[64] Kamer AR, Craig RG, Pirraglia E, Dasanayake AF, Norman RG, Boylan RJ, Nehorayoff A, Glodzik L, Brys M, de Leon M J (2009) TNF $\alpha$ and antibodies to periodontal bacteria discriminate between Alzheimer's disease patients and normal subjects. $J$ Neuroimmunol 216, 92-97. 
[65] Soscia SJ, Kirby JE, Washicosky KJ, Tucker SM, Ingelsson M, Hyman B, Burton MA, Goldstein LE, Duong S, Tanzi RE, Moir RD (2010) The Alzheimer’s disease-associated amyloid beta-protein is an antimicrobial peptide. PLoS One 5, e9505.

[66] Zaiou M (2007) Multifunctional antimicrobial peptides: therapeutic targets in several human diseases. J Mol Med (Berl) 85, 317-329.

[67] Dennison SR, Morton LH, Harris F, Phoenix DA (2008) The impact of membrane lipid composition on antimicrobial function of an alpha-helical peptide. Chem Phys Lipids 151, 92102.

[68] Kawahara M, Ohtsuka I, Yokoyama S, Kato-Negishi M, Sadakane Y (2011) Membrane incorporation, Channel formation, and disruption of calcium homeostasis by Alzheimer's $\beta$ Amyloid protein. Int J Alzheimers Dis 2011, 304583.

[69] Holmes C, Cotterell D (2009) Role of infection in the pathogenesis of Alzheimer's disease. CNS Drugs 23, 993-1002.

[70] Itzhaki RF, Wozniak MA (2008) Herpes simplex virus type I in Alzheimer’s disease: the enemy with. J Alzheimers Dis 13, 393-405.

[71] Balin BJ, Little CS, Hammond CJ, Appelt DM, Whittum-Hudson JA, Gérard HC, Hudson AP (2008) Chlamydophila pneumoniae and the etiology of late-onset Alzheimer's disease. $J$ Alzheimers Dis 13, 371-380.

[72] Riviere GR, Riviere KH, Smith KS (2002) Molecular and immunological evidence of oral Treponema in the human brain and their association with Alzheimer's disease. Oral Microbiol Immunol 17, 113-118.

[73] Miklossy J (2011) Emerging roles of pathogens in Alzheimer’s disease. Expert Rev Mol Med 13, e30. 
[74] Poole S, Singhrao SK, Kesavalu L, Curtis MA, Crean StJ (2013) Determining the presence of periodontopathic virulence factors in short-term postmortem Alzheimer's disease brain tissue. J Alzheimers Dis 36, 665-677.

[75] de Oliveira C, Watt R, Hamer M (2010) Tooth brushing, inflammation, and risk of cardiovascular disease: results from Scottish Health Survey. BMJ 340, c2451.

[76] Paganini-Hill A, White SC, Atchison KA (2012) Dentition, dental health habits, and dementia: the Leisure World Cohort study. J Am Geriatr Soc 60, 1556-1563.

[77] Aida J, Kondo K, Kondo N, Watt RG, Sheiham A, Tsakos G (2011) Income inequality, social capital and self-rated health and dental status in older Japanese. Soc Sci Med 73, 15611568.

[78] Arai K, Sumi Y, Uematsu H, Miura H (2003) Association between dental health behaviours, mental/physical function and self-feeding ability among the elderly: a cross-sectional survey. Gerodontology 20, 78-83.

[79] Griffin SO, Jones JA, Brunson D, Griffin P, Bailey WB (2012) Burden of oral diseases among older adults and implications for public health priorities. Am J Public Health 102, 411418.

[80] Philip P, Rogers C, Kruger E, Tennant M (2012) Oral hygiene care status of elderly with dementia and in residential aged care facilities. Gerodontology 29, e306-e311.

[81] Friedlander AH, Norman DC, Mahler ME, Norman KM, Yagiela JA (2006) Alzheimer's disease: psychopathology, medical management and dental implications. J Am Dent Assoc 137, $1240-1251$.

[82] Chapple I, Milward MR, Dietrich T (2007) The prevalence of inflammatory periodontitis is negatively associated with serum antioxidant concentrations. $J$ Nutr 137, 657-664. 
[83] Kinane DF, Marshall GJ (2001) Periodontal manifestations of systemic disease. Aust Dent Jl 46, 2-12.

[84] Hasturk H, Kantarci A, Van Dyke TE (2012) Oral inflammatory diseases and systemic inflammation: role of the macrophage. Front Immunol 3 1-11.

[85] Socransky SS, Haffajee AD, Cugini MA, Smith C, Kent RL (1998) Microbial complexes in subgingival plaque. J Clin Periodontol 25, 134-144.

[86] Holt SC, Ebersole JL (2005) Porphyromonas gingivalis, Treponema denticola, and Tannerella forsythia: the "red complex", a prototype polybacterial pathogenic consortium in periodontitis. Periodontology 38, 72-122.

[87] Bahrani-Mougeot FK, Paster BJ, Coleman S, Ashar J, Barbuto S, Lockhart PB (2008) Diverse and novel oral bacterial species in blood following dental procedures. J Clin Microbiol 46, 2129-2132.

[88] DeStefano F, Anda RF, Kahn HS, Williamson DF, Russell CM. (1993) Dental disease and risk of coronary artery disease and mortality. BMJ 306, 688-691.

[89] Scannapieco FA, Bush RB, Paju S (2003) Associations between periodontal disease and risk for atherosclerosis, cardiovascular disease, and stroke. A systematic review. Ann Periodontal 8, 38-53.

[90] Gleissner C, Willershausen B, Kaesser U, Bolten WW (1998) The role of risk factors for periodontal disease in patients with rheumatoid arthritis. Eur J Med Res 3, 387-392.

[91] Bartold PM, Marshall RI Haynes DR (2005) Periodontitis and rheumatoid arthritis: a review. J Periodontol 76, 2066-2074.

[92] Pischon N, Pischon T, Kroger J, Gulmez E, Kleber BM, Bernimoulin JP, Landau H, Brinkmann PG, Schlattmann P, Zernicke J, Buttgereit F, Detert J (2008) Association among 
rheumatoid arthritis, oral hygiene, and periodontitis. J Periodontol 79, 979-986.

[93] Grossi SG, Genco RJ (1998) Periodontal disease and diabetes mellitus: a two-way relationship. Ann Periodontol 3, 51-61.

[94] Wilson-Pauwels L, Akesson E, Stewart P, Spacey S (1988) Cranial Nerves in Health and Disease. Decker BC Inc., Toronto.

[95] Danielyan L, Schäfer R, von Ameln-Mayerhofer A, Buadze M, Geisler J, Klopfer T, Burkhardt U, Proksch B, Verleysdonk S, Ayturan M, Buniatian GH, Gleiter CH, Frey WH 2nd (2009) intranasal delivery of cells to the brain. Eur J Cell Biol 88, 315-324.

[96] Johnson NJ, Hanson LR, Frey WH (2010) trigeminal pathway delivers a low molecular weight drug from the nose to the brain and orofacial structures. Mol Pharm 7, 884-893.

[97] Foschi F, Izard J, Sasaki H, Sambri V, Prati C, Müller R, Stashenko P (2006) Treponema denticola in disseminating endodontic infections. $J$ Dent Res 85, 761-765.

[98] Haraszthy V, Zambon J, Trevisan M, Zeid M, Genco R (2000) Identification of periodontal pathogens in atheromatous plaques $J$ Periodontol 71, 1554-1560.

[99] Belstrøm D, Holmstrup P, Damgaard C, Borch TS, Skjødt MO, Bendtzen K, Nielsen CH (2011) The atherogenic bacterium Porphyromonas gingivalis evades circulating phagocytes by adhering to erythrocytes. Infect Immun 79, 1559-1565.

[100] Arrive E, Letenneur L, Matharan F, Laporte C, Helmer C, Barberger-Gateau P, Miquel JL, Dartigues JF (2012) Oral health condition of French elderly and risk of dementia: a longitudinal cohort study. Community Dent Oral Epidemiol 40, 230-238.

[101] Syrjala AM, Ylostalo P, Ruoppi P, Komulainen K, Hartikainen S, Sulkava R, Knuuttila M (2012) Dementia and oral health among subjects aged 75 years or older Gerodontology 29, 3642. 
[102] Yamamoto T, Kondo K, Nakada M, Aida J, Hirata Y (2012) Association between selfreported dental health status and onset of dementia: a 4-year prospective cohort study of older Japanese adults from the Aichi Gerontological Evaluation Study (AGES) Project Psychosom Med 74, 241-248.

[103] Mooijaart SP, Gussekloo J, Frolich M, Jolles J, Stott DJ, Westendorp RGJ, de Craen AJM (2005) Homocysteine, vitamin B-12, and folic acid and the risk of cognitive decline in old age: the Leiden 85-plus study. Am J Clin Nutr 82, 866-871.

[104] Engelborghs S, Gilles C, Ivanoiu A, Vandewoude M (2014) Rationale and clinical data supporting nutritional intervention in Alzheimer’s disease. Acta Clin Belg 69, 17-24. [105] Sparks Stein P, Steffen MJ, Smith C, Jicha G, Ebersole JL, Abner E, Dawson D (2012) Serum antibodies to periodontal pathogens are a risk factor for Alzheimer's disease. Alzheimers Dement 8, 196-203.

[106] Chen JQ, Cammarata PR, Baines CP, Yager JD (2009) Regulation of mitochondrial respiratory chain biogenesis by estrogens/estrogen receptors and physiological, pathological and pharmacological implications. Biochem Biophys Acta 1793 1540-1570.

[107] Desvarieux M, Schwahn C, Volzke H, Demmer RT, Ludemann J, Kessler C, Jacobs DR, John U, Kocher T (2004) Gender differences in the relationship between periodontal disease, tooth loss and atherosclerosis. Stroke 35, 2029-2035

[108] Jagannathachary S, Kamaraj D (2010) Obesity and periodontal disease. J Indian Soc Periodontol 14, 96-100.

[109] Neto JBC, Rosa EF, Pannuti CM, Romito GA (2012) Smoking and periodontal disease: a review Braz Oral Res 26 25-31. 
[110] Shchipkova AY, Nagaraja HN, Kumar PS (2010) Subgingival microbial profiles of smokers with periodontitis. J Dent Res 89, 1247-1253.

[111] Kumar PS, Matthews CR, Joshi V, de Jager M, Aspiras M (2011) Tobacco smoking affects bacterial acquisition and colonization in oral biofilms. Infect Immun 79, 4730-4738.

[112] Kumar PS (2012) Smoking and the subgingival ecosystem: a pathogen-enriched community. Future Microbiol 7, 917-919.

[113] Gautam DK, Jindal V, Gupta SC, Tuli A, Kotwai B, Thakur R (2011) Effect of cigarette smoking on the periodontal health status: a comparative, cross-sectional study. J Indian Soc Periodontol 15, 383-387

[114] White HK, Levin ED (2004) Chronic transdermal nicotinic patch treatment effects on cognitive performance in age-associated memory impairment. Psychopharmacology 171, 465471.

[115] Borrell LN, Burt BA, Taylor GW (2005) Prevalence and trends in periodontitis in the USA: from the NHANES III to the NHANES 1988 to 2000. J Dent Res $\mathbf{8 4 , 9 2 4 - 9 3 0 . ~}$ [116] Borrell LN, Crawford ND (2008) Social disparities in periodontitis among United States adults 1999-2004. Community Dent Oral Epidemiol 36, 383-391.

[117] Sabbah W, Tsakos G, Sheiham A, Watt RG (2009) The role of health-related behaviours in the socioeconomic disparities in oral health. Soc Sci Med 68, 298-303.

[118] Sharp ES, Gatz M (2011) The relationship between education and dementia: an updated systematic review Alzheimer Dis Assoc Disord 25, 289-304.

[119] Kornman KS, Crane A, Wang HY, di Giovine FS, Newman MG, Pirk FW, Wilson TG Jr, Higginbottom FL, Duff GW (1997) The interleukin-1 genotype as a severity factor in adult periodontal disease. J Clin Periodontol 24, 72-77. 
[120] Galbraith GMP, Hendley TM, Sanders JJ, Palesch Y, Pandey JP (1999) Polymorphic cytokine genotypes as markers of disease severity in adult periodontitis. J Clin Periodontol 26, 705-709.

[121] Shao MY, Huang P, Cheng R, Hu T (2009) Interleukin-6 polymorphisms modify the risk of periodontitis: a systematic review and meta-analysis. J Zheijang Univ Sci B 10, 920-927. [122] Shearer DM, Thomson WM, Caspi A, Moffitt TE, Broadbent JM, Poulton R (2011) Intergenerational continuity in periodontal health: findings from the Dunedin Family History Study. $J$ Clin Periodontol 38, 301-309.

[123] Selye H (1974) Stress without Distress. Lippincott, New York.

[124] Miller DB, O’Callaghan JP (2002) Neuroscience aspects of the response to stress. Metabolism 51 (6 Suppl 1), 5-10.

[125] Lupien SJ, Gillin CJ, Hauger RL (1999) Working memory is more sensitive than declarative memory to the acute effects of corticosteroids: a dose-response study in humans. Behav Neurosci 113, 420-430.

[126] Hoffman R, Al'Absi M, (2003) The effect of acute stress on subsequent neuropsychological test performance. Arch Clin Neuropsychol 19, 497-506. [127] Wolf OT, Schommer NC, Hellhammer DH, Reischies FM, Kirschbaum C (2002) Moderate psychosocial stress appears not to impair recall of words learned 4 weeks prior to stress exposure. Stress 5, 59-64.

[128] Dhabhar FS, McEwen BS (1997) Acute stress enhances while chronic stress suppresses cell-mediated immunity in vivo: a potential role for leukocyte trafficking. Brain Behav Immun 11, 286-306.

[129] Oitzl MS, Champagne DL, van der Veen R, de Kloet ER (2010) Brain development under 
stress: hypotheses of glucocorticoid actions revisited. Neurosci Biobehav Rev 34, 853-866. [130] Pomerleau CS, Pomerleau OF (1987) The effects of a psychological stressor on cigarette smoking and subsequent behavioral and physiological responses. Psychophysiology 24, 278-285. [131] Cooper ML, Russell M, Skinner JB, Frone MR, Mudar P (1992). Stress and alcohol use: moderating effects of gender, coping, and alcohol expectancies. J Abnorm Psychol 101, 139-152. [132] Torres SJ, Nowson CA (2007) Relationship between stress, eating behaviour, and obesity. Nutrition 23, 887-894.

[133] Akcali A, Huck O, Tenebaum H, Davideau J L, Buduneli N. (2013) Periodontal diseases and stress: a brief review. J Oral Rehabil 40, 60-68.

[134] Giannopoulou C, Kamma JJ, Mombelli A (2003) Effect of inflammation, smoking and stress on gingival crevicular fluid cytokine level. J Clin Periodontol 30, 145-153.

[135] Turnbull AV, Rivier CL (1999) Regulation of the hypothalamic-pituitary-adrenal axis by cytokines: actions and mechanisms of action. Physiol Rev 79, 1-71.

[136] Li G, Cherrier MM, Tsuang DW, Petrie EC, Colasurdo EA, Craft S, Schellenberg GD, Peskind ER, Raskind MA, Wilkinson CW (2006) Salivary cortisol and memory function in human aging. Neurobiol Aging 27, 1705-1714.

[137] McEwan BS (2007) Physiology and neurobiology of stress and adaptation: central role of the brain. Physiol Rev 87, 873-904.

[138] Gouin JP, Hantsoo L, Kiecolt-Glaser JK (2008) Immune dysregulation and chronic stress among older adults: a review. Neuroimmunomodulation 15, 251-259.

[139] Gusev NB, Bogatcheva NV, Marston SB (2002) Structure and properties of small heat shock proteins (sHsp) and their interaction with cytoskeletal proteins. Biochemistry 67, 511-519. 
[140] Dou F, Netzer WJ, Tanemura K, Li F, Hartl FU, Takashima A, Gouras GK, Greengard P, Xu H (2003) Chaperones increase associations of tau protein with microtubules. Proc Natl Acad Sci U S A 100, 721-726.

[141] Obata T, Yaffe MB, Leparc GG, Piro ET, Maegawa H, Kashiwagi A, Kikkawa R, Cantley LC (2000) Peptide and protein library screening defines optimal substrate motifs for AKT/PKB. J Biol Chem 17, 108-115.

[142] Scheinfeld M H, Roncarati R, Vito P, Lopez P A, Abdallah M, D’Adamio L. (2002) Jun $\mathrm{NH}_{2}$-terminal kinase (JNK) interacting protein 1 (JIP1) binds the cytoplasmic domain of the Alzheimer’s beta-amyloid precursor protein (APP) J Biol Chem 277, 3767-3775.

[143] Zhu X, Raina AK, Lee HG, Casadesus G, Smith MA, Perry G (2004) Oxidative stress signaling in Alzheimer’s disease. Brain Res 1000, 32-39. 


\section{Legends}

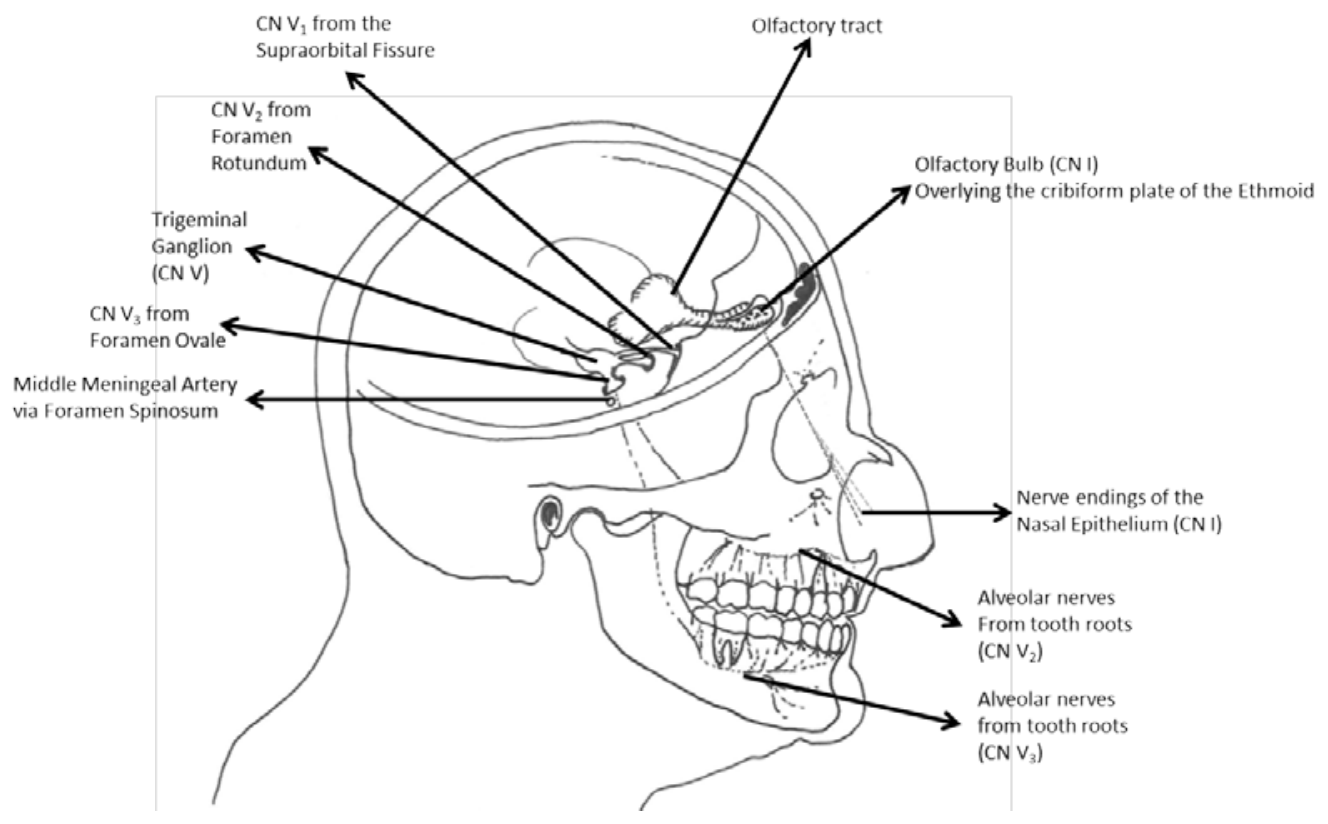

Figure 1. Nerve pathways from the oral and nasal cavity to the brain, showing the 2nd and 3rd branches of the Trigeminal (CN V) and the Olfactory nerve (CN I). The middle meningeal artery enters the brain at the foramen spinosum in the lateral portion of the greater wing of the sphenoid, and then follows the cranial base and lateral potions of the vault, supplying the dura and bones of the calvarium. 